\title{
10.04
}

\section{Controle sanitário de fronteiras: trânsito internacional de pessoas na Copa do Mundo de 2014}

Border sanitary control: international people's traffic in the World Cup of 2014

\author{
Aline Daiane dos Reis Lima \\ Farmacêutica. Especialista em Direito Sanitário. Especialista em Vigilância Sanitária. \\ Fundação Oswaldo Cruz. Brasília, Brasil.
}

Resumo: Enquanto as viagens e o comércio internacionais trazem muitos benefícios à saúde ligados ao desenvolvimento econômico, eles também podem causar riscos à saúde pública que podem se disseminar internacionalmente em aeroportos, portos e fronteiras terrestres por meio de pessoas, animais, alimentos, bagagens, cargas, meios de transporte, mercadorias e encomendas postais. Devido ao aumento do tráfego de pessoas durante a Copa do Mundo de 2014 que acontecerá no Brasil, percebe-se a necessidade da efetiva aplicação do Regulamento Sanitário Internacional (2005) para que seja garantido o direito fundamental a saúde da população brasileira e aos visitantes por meio da identificação de emergências de saúde pública de importância internacional e das respostas a tais eventos.

Palavras-chave: Regulamento Sanitário Internacional; Copa do Mundo; trânsito de pessoas.

Keywords: International Health Regulations; World Cup; people’s traffic.

\section{Introdução}

A Federação Internacional de Futebol Associado (FIFA) é a instituição responsável pela definição e aplicação das regras mundiais do futebol, realizando diversos eventos, dentre eles a Copa do Mundo, realizada a cada quatro anos, em um país sede, contando com a participação das melhores seleções do mundo. Em 2014 o Brasil sediará este torneio.

Durante a Copa do Mundo, milhares de pessoas de diversos países deslocamse para o país sede para acompanhar os jogos. O turismo desportivo tem recebido crescente atenção como significativa fonte de geração de receita e contribuindo com grandes benefícios econômicos para as cidades, as regiões e os países. Por outro lado, percebe-se a necessidade do monitoramento do trânsito internacional de pessoas para a determinação dos riscos à saúde e minimização do risco de disseminação de doenças. 
Estima-se que 600 mil turistas estrangeiros e 3 milhões de brasileiros desloquem-se para as cidades-sede para assistirem os jogos no Brasil. O Sistema de Saúde Brasileiro enfrentará oportunidades e desafios no que tange os serviços de saúde, preparando-se para atender ao aumento da demanda por atendimentos e as alterações do perfil epidemiológico populacional. Desta forma, o Governo Federal instalou a Câmara Temática de Saúde, que se reúne periodicamente, buscando a promoção da coordenação das ações de saúde durante o evento, o apoio para a elaboração de projetos de aprimoramento da infraestrutura e o acompanhamento da execução destas ações (Portal da Copa, 2012 a).

O Sistema de Vigilância em Saúde deverá ser aperfeiçoado, por meio das ações de fiscalização sanitária dos portos, aeroportos e fronteiras, da preparação para as emergências de saúde pública e da notificação de doenças transmissíveis de relevância epidemiológica no país. O Governo Federal criou a Força Nacional do Sistema Único de Saúde (FN-SUS), para a atuação em situações de catástrofe e emergências de grandes proporções no Brasil durante a Copa do Mundo, por meio do Decreto nํ 7.616, de 17 de novembro de 2011 (Portal da Copa, 2012 a).

A Lei Geral da Copa (LGC), Lei no 12.663, de 5 de junho de 2012, foi regulamentada pelo Decreto $\mathrm{n}^{-} \mathbf{7 . 7 8 3}$, de 7 de agosto de 2012 , estabelecendo as medidas relativas à Copa das Confederações de 2013 e à Copa do Mundo de 2014. A concessão de vistos de entrada é prevista no artigo 19 da LGC para aqueles que desejarem assistir os jogos da Copa do Mundo no Brasil, sem restrição à nacionalidade, raça ou credo. O inciso $\mathrm{XI}$, do referido artigo, estabelece que "espectadores que possuam ingressos ou confirmação de ingressos válidos para qualquer evento e todos os indivíduos que demonstrem seu envolvimento oficial com os eventos" terão seus vistos concedidos e válidos até dia 31 de dezembro de 2012. No artigo 55 da LGC, são definidas as responsabilidades de fornecimento de segurança, vigilância sanitária, saúde e serviços médicos, alfândega e imigração, que serão disponibilizados para a realização do evento.

O processo de globalização proporcionou o desenvolvimento e a diminuição dos custos para o tráfego internacional de pessoas e mercadorias, desenvolvendo o comércio e o turismo mundial, como pode ser observado na Copa do Mundo, um evento de repercussão global. Por sua vez, a globalização também impulsionou a transnacionalização dos riscos à saúde, facilitada pelo transporte e pela transmissão 
de doenças, novas e reemergentes, por meio de pessoas, animais, alimentos, bagagens, cargas, meios de transporte, mercadorias e encomendas postais, podendo expor toda a população mundial a crises sanitárias, epidemias, e pandemias (Buss, 2007).

Considerando a significativa majoração do tráfego internacional de pessoas e mercadorias durante a Copa do Mundo de 2014, assim como a responsabilidade pela vigilância sanitária e pela proteção à saúde, o país deverá controlar as fronteiras para a mitigação de transmissão de doenças advindas do turismo desportivo conforme estabelecido no Regulamento Sanitário Internacional (RSI), a principal norma internacional em vigor sobre a transnacionalização dos riscos, plenamente aplicável no Brasil.

Este artigo tem como objetivo ressaltar a necessidade do controle do trânsito internacional de pessoas visando à minimização de riscos à saúde no Brasil, país sede do evento Copa do Mundo de 2014.

Para a construção deste artigo de revisão bibliográfica, foram selecionados livros, artigos e leis tendo como descritor de busca: trânsito internacional de pessoas, vigilância sanitária, controle sanitário de fronteiras, Regulamento Sanitário Internacional, Copa do Mundo. A revisão foi realizada com artigos publicados em revistas científicas, pesquisados na base de dados da Bireme, por meio dos serviços da Medline, Scielo e Lilacs. Também foram acessados sites oficiais (Federação Internacional de Futebol Associado, Organização Mundial de Saúde, Organização Pan-americana de Saúde e Ministério da Saúde) para a obtenção de notícias atualizadas sobre o assunto.

\section{Transnacionalização dos riscos à saúde}

As epidemias amedrontam o ser humano e perpassam por todos os tempos históricos. O comércio internacional intensificou as relações mercadológicas, porém influíram também no aparecimento de surtos epidêmicos pela ultrapassagem das doenças pelas fronteiras geográficas, favorecendo a transnacionalização dos riscos à saúde da população mundial. A identificação da transmissão de doenças pelo deslocamento de pessoas remete à peste da Etiópia que se disseminou pela Grécia em 431 a.C. Esta pandemia alastrou-se pela Ásia, África e Europa (Castro, 2012). 
Na Idade Média, começou-se a estudar, na região comercial do mediterrâneo, o contágio e a contenção das doenças. Adotava-se o isolamento (ou quarentena) de pacientes com doenças graves para que estas não fossem transmitidas aos indivíduos saudáveis. Estas ações originaram o sistema de vigilância epidemiológica para a proteção contra as doenças (Costa, 2003).

A descoberta da América, em 1492, favoreceu a disseminação global das doenças que ainda não assolavam o continente. O perfil das doenças do velho e do novo mundo era muito contrastante devido às condições ambientais, alimentação e presença de vetores biológicos transmissores de doenças. A população americana não tinha imunidade natural para as enfermidades vindas do velho mundo. Acreditase que, neste contexto, houve a unificação microbiana no mundo. Porém, somente três séculos depois, a população mundial e os agentes públicos tomaram conhecimento dos riscos da disseminação das doenças em escala global (Berlinger, 1999).

Nos últimos séculos, a população mundial foi atingida por algumas epidemias, como Síndrome Aguda Respiratória Grave (SARS), dengue, gripe aviária (H5N1), influenza A subtipo H1N1, encefalopatia espongiforme bovina, febres hemorrágicas virais, que demandaram grande mobilização dos países quanto à segurança sanitária, às restrições comportamentais, comerciais e à mobilidade das pessoas.

Os desafios da globalização para o gerenciamento de doenças infecciosas exigem respostas de governança. Para os desafios encontrados dentro do país, a resposta do governo se concentra na cooperação interestadual para minimizar a disseminação da doença. Desafios entre países exigem estratégias que reduzam a prevalência da doença por meio da melhoria da saúde pública interna (Fidler, 2003).

Nestas ocasiões de crise sanitária mundial, em que estão inseridas as pandemias, constitui-se um Estado de exceção em nome da saúde pública. Nestes casos, há restrição dos direitos humanos em vista da preservação da vida e da segurança internacional, sobrepondo o interesse coletivo sobre os interesses individuais. O estabelecimento do Estado de exceção nas pandemias é justificado pela dependência de um procedimento de cooperação internacional (Ventura, 2010).

A interdependência técnica, cultural e econômica entre as nações universaliza as transações comerciais e possibilita a maior circulação de produtos e de pessoas. A globalização origina a possibilidade da transnacionalização das doenças 
transmissíveis, sejam elas novas ou reemergentes. A facilitação do comércio e das viagens internacionais implica no transporte de microrganismos por meio de pessoas, objetos, animais, insetos e alimentos. Aponta-se a necessidade e a importância do estabelecimento de redes globais de diagnóstico e vigilância em saúde (Buss, 2007). A definição de legislação internacional, que vise o controle e a eliminação de doenças de importância global, torna-se fundamental para a verificação de eventos epidêmicos e a previsão de ameaças e de pandemias com antecedência.

\section{Regulamento Sanitário Internacional e o direito à saúde}

O direito internacional tem como princípio geral o respeito aos direitos humanos. A dignidade da pessoa humana é superior aos interesses dos Estados e deve ser protegida, podendo sobrepor os princípios de soberania e ingerência (Varella, 2010). Os direitos humanos foram garantidos por meio da Declaração Universal dos Direitos Humanos em 1948 para a proteção do ser humano em resposta às atrocidades cometidas nos períodos de guerra.

A Organização Mundial da Saúde (OMS) iniciou suas atividades em abril de 1948 com o objetivo basilar de atingir o nível mais elevado possível de saúde a todas as pessoas, conforme estabelecido no artigo $1^{\circ}$ da sua Constituição. Além disto, 0 artigo $2^{\circ}$ da referida Constituição define as responsabilidades da OMS de atuar como autoridade internacional de saúde e de fornecer assistência em casos de urgências e emergências de saúde (Castro, 2012). Conforme explicitado por Periago \& Stepke (2007), a comunidade internacional deve fornecer fundamentos conceituais e operacionais para a construção de um bem comum público e universal, para que a saúde seja oferecida a todos os seres humanos.

O RSI é um instrumento jurídico internacional vinculante, organizado pela OMS, que visa à aliança global de alerta e à resposta frente às epidemias, para promover a segurança sanitária mundial (Gonzalo, 2007). O RSI propõe segurança máxima contra a propagação das ameaças e dos riscos à saúde pública, respeitando a dignidade, os direitos humanos e as liberdades fundamentais, para que o trânsito e o comércio internacionais sejam minimamente afetados (Mendoza, 2007).

O primeiro RSI foi adotado em 1951, e em 1969 foi publicado um novo RSI, com aplicação restrita a cólera, a peste e a febre amarela. O Regulamento sofria várias críticas, visto que, mesmo atendendo aos objetivos a que se propunha, era 
pouco eficiente para o controle das doenças que emergiam no mundo em globalização. O Regulamento Sanitário Internacional foi revisado em maio de 2005 e entrou em vigor em 15 e junho de 2007. O RSI (2005) foi adotado na 58a Assembleia Mundial da Saúde em maio de 2005 em Genebra (Suíça), e tornou-se juridicamente obrigatório em qualquer Estado Membro da OMS que não tenha vetado ou manifestado reservas ao Regulamento até dezembro de 2006. Conforme o artigo $2^{\circ}$ do RSI, o propósito e a abrangência do RSI são:

[...] prevenir, proteger, controlar e dar uma resposta de saúde pública contra a propagação internacional de doenças, de maneiras proporcionais e restritas aos riscos para a saúde pública, e que evitem interferências desnecessárias com 0 tráfego e 0 comércio internacionais (WHO, 2008).

O atual RSI (2005) ampliou o seu alcance e aumentou a segurança sanitária mundial, minimizando a interferência no trânsito de pessoas e no comércio internacional (Fidler, 1996). O intenso tráfego internacional, advindo da globalização e das mudanças epidemiológicas, incitou a implementação do RSI, propondo estratégias de vigilância e controle de enfermidades transmissíveis que possuem potencial pandêmico (Teixeira et al, 2009).

O novo RSI (2005) enfatiza a colaboração internacional para a notificação dos alertas de saúde. O aparecimento de doenças emergentes e reemergentes instigou a revisão do Regulamento, estimulando a agilidade para a notificação destes agravos à saúde. Ressalta também a transparência e a velocidade das comunicações de eventos de saúde pública de importância internacional, o fortalecimento dos sistemas de vigilância em saúde e a melhoria dos procedimentos para o controle das fronteiras e do transporte internacional (Gonzalo, 2007). Para isto, o RSI (2005) determina a adoção de Pontos Focais Nacionais em todos os Estados Membros capazes de identificar e notificar os eventos e os agravos ocorridos em seus territórios.

Conforme definição do artigo 1ำ do RSI (2005), quarentena é "a restrição das atividades e/ou o separação de pessoas suspeitas de pessoas que não estão doentes ou de bagagens, contêineres, meios de transporte ou mercadorias suspeitos, de maneira a evitar a possível propagação de infecção ou contaminação". O RSI (2005) também define o tratamento dos produtos e das pessoas que passam pelo país como potenciais causadores e propagadores de doenças. $\mathrm{O}$ artigo 18 do RSI dispõe as recomendações relativas a pessoas, bagagens, cargas, contêineres, meios de transporte, mercadorias e encomendas postais que podem ser submetidos a 
quarentena em caso de detecção de risco à saúde pública. Ainda, o artigo 23 determina que a inspeção de bagagens, cargas, contêineres, meios de transporte, mercadorias, encomendas postais e restos humanos são medidas de saúde observadas na entrada e na saída dos viajantes do país.

O RSI (2005) prevê diversas restrições ao trânsito de pessoas e o impedimento de entrada de viajantes nos países para a prevenção do alastramento de riscos potenciais. Com a evolução do conceito de saúde pública e o incremento da movimentação mundial facilitada de pessoas e de bens de consumo, percebe-se a necessidade de aplicação do princípio da precaução. O princípio da precaução analisa os riscos e as possibilidades destes causarem danos. A sua aplicação ao contexto internacional visa proteger e preservar a saúde pública, bem como a segurança e a soberania nacional, tanto nas restrições ao trânsito de pessoas e mercadorias quanto ao comércio. A finalidade da precaução é de superar a prevenção, impondo a obrigação de vigilância na preparação da decisão e no acompanhamento das consequências. Este princípio requer responsabilidade política dos governantes, devido aos impactos econômicos e sociais das decisões tomadas (Dallari \& Ventura, 2002).

O RSI é um instrumento fundamental para a governança global e a mitigação da propagação internacional de doenças que apresentam potencial risco pandêmico por meio das notificações de eventos de importância internacional. O alastramento de doenças no mundo globalizado influi diretamente no trânsito de pessoas e no comércio internacional. Para a obtenção das metas cobiçadas pelo RSI, o Regulamento deve ser conduzido com princípios éticos, promovendo a cooperação entre todos os atores que participam em todos os níveis de aplicação, sejam eles local, nacional e internacional (Mendoza, 2007).

\section{Emergências de saúde pública de importância internacional}

O RSI define emergência de saúde pública de importância internacional (ESPII) como:

[...] evento extraordinário, o qual é determinado, como estabelecido neste regulamento:

- por constituir um risco de saúde pública para outro Estado por meio da propagação internacional de doenças;

- por potencialmente requerer uma resposta internacional coordenada (WHO, 2008). 
$\mathrm{O}$ atual RSI institui medidas para ampliar a detecção e a resposta à possível propagação de doenças internacionalmente. São considerados eventos capazes de constituir ESPII aqueles nos quais efetivamente ocorre o dano ou causam risco potencial, contemplando doenças de origem microbiológica, química, radionuclear ou decorrentes de desastres ambientais (Carmo; Penna \& Oliveira, 2008). Desta forma, cabe aos Estados adotar medidas que, além de serem eficazes na identificação de eventos danosos, sejam capazes de prevenir os potenciais riscos à população.

A aplicação das normas internacionais pelos sistemas nacionais de vigilância epidemiológica visando à contenção de doenças com potencial pandêmico foi facilitada pelo RSI (2005), devido à definição dos eventos objetos de monitoramento, proposição e execução de ações que visem evitar ou diminuir a probabilidade de propagação internacional.

Cada país deve avaliar os eventos ocorridos em seu território para determinar se estes devem ser considerados como ESPII, utilizando o instrumento de decisão disposto no Anexo II do RSI de 2005 para depois notificá-los à OMS (WHO, 2008).

$\mathrm{Na}$ Figura 1, pode-se observar que são definidas doenças de notificação compulsória e doenças as quais o algoritmo de decisão deve ser avaliado para então ser realizada a notificação à OMS. Todas as informações de eventos enviadas à OMS são então analisadas para que sejam definidos ou não como ESPII (Ferreira \& Castro, 2011). Ressalta-se que não somente as doenças descritas no algoritmo devem ser notificadas à OMS. Aqueles eventos de causas indefinidas, de interesse nacional ou regional, também podem ser potenciais doenças de propagação internacional e precisam ser avaliadas conforme o instrumento de decisão do RSI. Este instrumento é muito relevante para que as tomadas de decisão sejam uniformizadas e harmonizadas em todos os Estados Membros.

A notificação do ESPII deve ser adequada e eficiente e, para isto, cada Estado Membro deverá ter um sistema de vigilância sanitária que envie as informações rapidamente de pontos periféricos para o Ponto Focal Nacional para que os dados sejam analisados prontamente (Carmo; Penna \& Oliveira, 2008). 
Figura 1: Instrumento de decisão para avaliação e notificação dos eventos que possam constituir ESPII

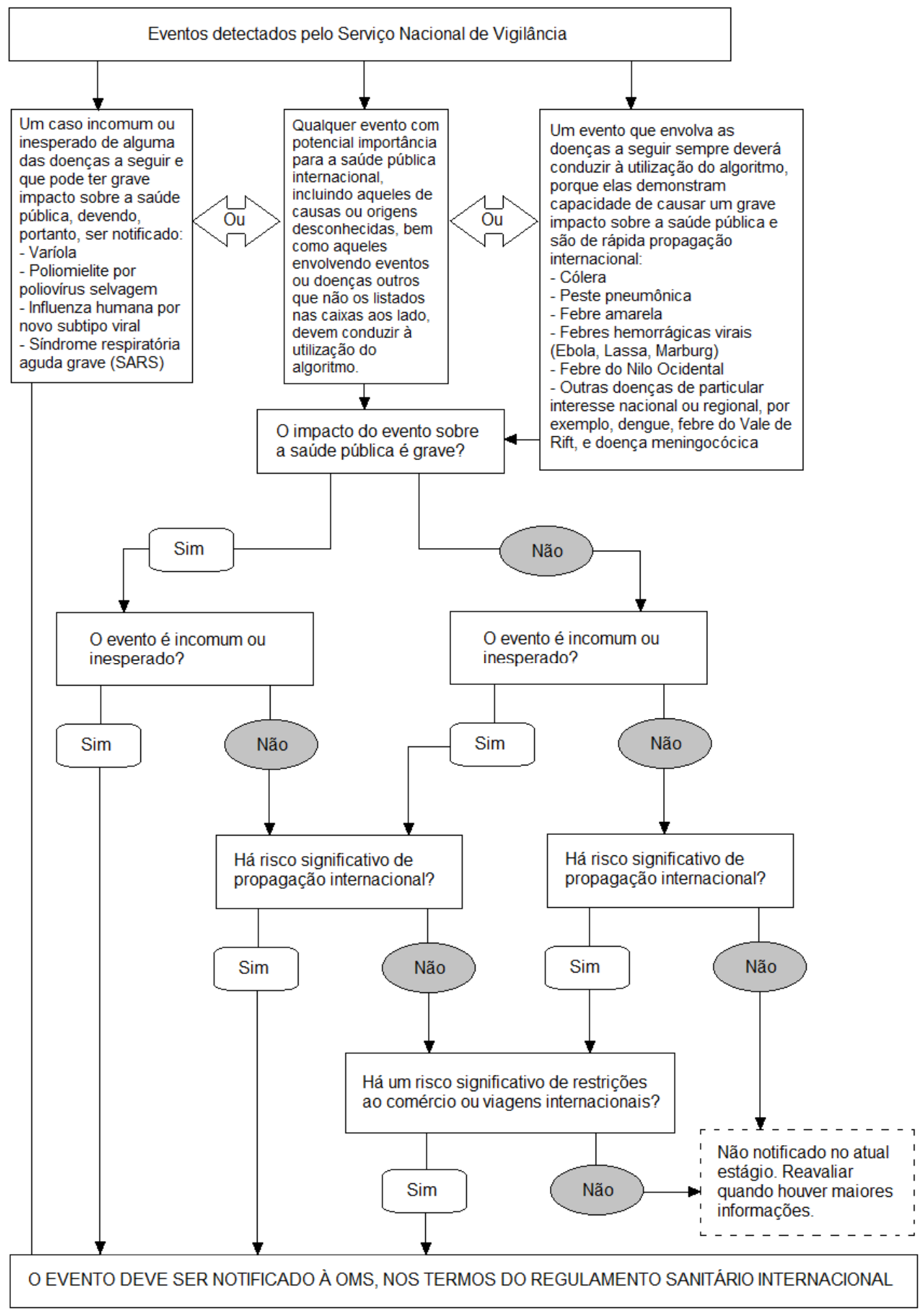

Fonte: Brasil. Regulamento Sanitário Internacional (2005). Brasília: Anvisa, 2009. 
O artigo 9 do RSI (2005) institui a possibilidade de aceitação de informações advindas de fontes não oficiais para o conhecimento de eventos que podem constituir uma ESPII. Na ocorrência destes casos, o Estado no qual o evento esteja acontecendo deve ser consultado e ele terá até 24 horas para confirmar ou desconsiderar a notificação identificada (Castro, 2012).

\section{Controle sanitário de fronteiras durante a Copa do Mundo}

O Congresso Nacional Brasileiro aprovou o RSI, por meio do Decreto Legislativo no 395 , de 9 de julho de 2009, comprometendo-se a prevenir e controlar a propagação das enfermidades dentro e fora de suas fronteiras. O Brasil é Estado Membro da OMS, portanto a implantação do RSI no país tem caráter vinculante.

Cada país deve designar um Ponto Focal Nacional para o RSI para atuar conjuntamente à OMS. A Portaria no 1.865/GM/MS, de 10 de agosto de 2006, estabeleceu a Secretaria de Vigilância em Saúde (SVS/MS) como Ponto Focal Nacional para o RSI. O Centro de Informações Estratégicas em Vigilância em Saúde (CIEVS) é o departamento da SVS/MS que recebe informações sobre a ocorrência de surtos e emergências epidemiológicas com potencial risco à saúde da população. O CIEVS opera 24 horas por dia, todos os dias do ano, para detectar e gerenciar as emergências de saúde pública, e coordenar as respostas e as intervenções adequadas a serem implantadas pelo MS e pelas secretarias estaduais e municipais de saúde (Brasil, 2006). Este Centro expande o uso de informações estratégicas e a comunicação de eventos à rede mundial de alertas e respostas (Carmo; Penna \& Oliveira, 2008). A Agência Nacional de Vigilância Sanitária (ANVISA) atua conjuntamente ao CIEVS na fiscalização de portos, aeroportos e fronteiras desempenhando ações de vigilância epidemiológica e de controle de vetores, conforme competência estabelecida no artigo $7^{\circ}$, $\S 3^{\circ}$, da Lei $n^{\circ} 9.782$ de 26 de janeiro de 1999.

O artigo $5^{\circ}$ do RSI prevê que todos os Estados Partes deverão desenvolver, fortalecer e manter as capacidades para detectar, avaliar, notificar e informar eventos de acordo com as especificações do Anexo I do referido Regulamento. O Brasil já estabeleceu as capacidades nacionais básicas constantes no Anexo I do RSI, como atividades de vigilância, informes, notificação, verificação, resposta e de colaboração e atividades referentes a portos, aeroportos e fronteiras terrestres. 
Estão sendo realizadas Câmaras Temáticas de Saúde, organizadas pelo Ministério da Saúde em parceria com os estados e os municípios, para o debate e a construção do planejamento e das diretrizes das ações de saúde que serão implantadas durante a Copa do Mundo de 2014. Todos os doze municípios que sediarão os jogos participam das reuniões: Belo Horizonte (MG), Brasília (DF) Cuiabá $(\mathrm{MT})$, Curitiba (PR), Fortaleza (CE), Manaus (AM), Natal (RN), Porto Alegre (RS), Recife (PE), Rio de Janeiro (RJ), Salvador (BA) e São Paulo (SP) (Portal da Copa, 2012 a).

A Organização Pan-Americana de Saúde (OPAS) e o MS realizaram a Primeira Reunião na América Latina em Ações do Setor da Saúde para Eventos de Massa/ V Reunião da Câmara Temática de Saúde para a Copa do Mundo de 2014, nos dias 12 e 13 de dezembro de 2011 no Brasil. Este evento proporcionou a troca de informações relativas à saúde entre os países da América Latina que sediaram e sediarão eventos de grande porte. O intercambio de experiências, com base nas definições do RSI, contribuiu para a preparação, a resposta e a cooperação regional durante eventos de massa, oferecendo subsídios às cidades-sede brasileiras para a Copa do Mundo de 2014 (OPAS, 2012).

A FN-SUS também prestará assistência ágil e efetiva às populações em território nacional e internacional, atingidas por catástrofes, epidemias ou crises assistenciais durante a Copa do Mundo. Os profissionais que atuarão na FN-SUS terão capacitação específica para atuarem em situações de calamidade. De acordo com o artigo $2^{\circ}$ da Resolução nํ4ㄱ, de 9 de junho de 2011, a FN-SUS é organizada pelo MS e pretende garantir a integralidade da assistência em situações emergenciais ou de risco, conduzida sob os princípios básicos do SUS: equidade, integralidade e universalidade. A FN-SUS proverá respostas rápidas e eficientes em situações de calamidade e urgências em todo o território nacional e, extraordinariamente em outros países, em casos de acordos de cooperação internacional. As equipes da Força Nacional contarão com a estrutura e os serviços da Defesa Civil, dos órgãos de vigilância e assistência e do Corpo de Bombeiros. Uma equipe de 320 pessoas que integrará a FN-SUS, de todas as cidades-sede da Copa do Mundo, foi treinada em setembro de 2012 para a gestão da saúde em situação de urgência e emergência (Portal da Copa, 2012 b). 
Em vista do intenso trânsito de pessoas em alguns pontos de entrada e saída do Brasil durante a Copa do Mundo, alguns procedimentos deverão ser intensificados para a ágil ação das autoridades sanitárias brasileiras, adotando-se medidas de controle sanitário de viajantes na entrada e na saída do território nacional pelos servidores de Portos, Aeroportos, Fronteiras e Recintos Alfandegados (PAF). De acordo com o artigo 71 do Regimento Interno da Anvisa, a Portaria oㅜ 593, de 25 de agosto de 2000, a Agência é responsável pelas atividades de controle sanitário, de vigilância epidemiológica e de controle de vetores em portos, aeroportos, pontos de passagem de fronteiras, terminais de passageiros e cargas e estações aduaneiras. $O$ Brasil exige a apresentação do Certificado Internacional de Vacinação e Profilaxia (CIVP) válido para a entrada de turistas no país. A exigência do CIVP é prevista no RSI. Conforme a Nota Técnica no 06/07/DEVEP/SVS/MS, o Brasil recomenda a vacinação contra a febre amarela para viajantes procedentes de áreas endêmicas ou com destino a estas áreas, ou para viajantes com destino às áreas nacionais de risco para transmissão dela (Anvisa, 2005).

A Gerência de Portos Aeroportos e Fronteiras da Anvisa (GGPAF) instituiu o Sagarana, o sistema de gestão de riscos nos portos, aeroportos e fronteiras do Brasil. O sistema visa garantir o controle sanitário de portos, aeroportos e fronteiras, bem como a proteção à saúde do viajante, dos meios de transporte e dos serviços submetidos à vigilância sanitária. Este novo sistema permite a identificação de informações em tempo real sobre a inspeção de aeronaves, navios, transportes terrestres. Os postos de monitoramento são submetidos à rotina semanal de gestão do sistema, que contempla a avaliação da programação das atividades, o preenchimento dos questionários de fiscalização e as suas conclusões (Anvisa, 2011).

Recentemente foi publicada pela Anvisa a RDC ํㅡ 2, de 4 de janeiro de 2013, que "estabelece as normas de controle sanitário sobre a entrada de bens e produtos procedentes do exterior destinados à utilização em eventos de grande porte no País". A Resolução simplifica a entrada dos alimentos, medicamentos, cosméticos, perfumes, materiais médicos e outros produtos de interesse à saúde humana de uso exclusivo pelas comitivas e pelas delegações internacionais credenciadas durante os megaeventos no Brasil, como a Copa do Mundo de 2014. Conforme definido na 
norma, os produtos de consumo pessoal ficarão dispensados de controle pela Anvisa e as substâncias proscritas no Brasil continuam proibidas de serem importadas.

\section{Considerações finais}

A reorganização mundial, caracterizada pelo intenso fluxo de pessoas, bens e mercadorias entre os países, aumenta a possibilidade de transnacionalização dos riscos à saúde global. Ao mesmo tempo em que favorece o desenvolvimento do país, pode causar impacto negativo tanto na saúde da população quanto na economia, afetando o comércio de bens e serviços, sobretudo relacionados ao turismo e às viagens. Os riscos e as doenças ultrapassam as fronteiras favorecendo a disseminação internacional de doenças. Desta forma, percebe-se a necessidade de harmonização da legislação internacional relativa a este tema.

Os padrões mínimos de segurança internacional devem ser atingidos para a proteção da saúde mundial, contudo deve-se haver comprometimento político nos níveis regional, nacional e internacional por meio da cooperação entre os países e as instituições. A governança global da saúde deve estar comprometida com os direitos do ser humano e também deve ser responsável por prover uma estrutura básica eficiente capaz de identificar, notificar e responder os eventos que apresentam riscos de propagação internacional.

A Copa do Mundo é um evento global e a vigilância em saúde brasileira deve estar atenta ao surgimento de emergências em saúde pública por meio de monitoramento, proposição e execução de ações que visem evitar ou diminuir a probabilidade de propagação internacional de doenças durante a realização do evento. O Brasil está se preparando para a realização dos jogos de 2014 , do ponto de vista sanitário, por meio do Sistema Sagarana, do FN-SUS e das discussões nas Câmaras Temáticas de Saúde. Em virtude da LGC, todos os turistas que pretenderem assistir aos jogos da Copa do Mundo terão a concessão dos seus vistos de entrada no Brasil e deverão ser atendidos pelos sistemas de segurança, vigilância sanitária, saúde, serviços médicos, alfândega e imigração.

O RSI (2005) mostra-se promissor para minimização da propagação internacional de enfermidades e para a comunicação de surtos epidêmicos e outros riscos durante o torneio de 2014. O Brasil vem trabalhando para alcançar o cumprimento das Capacidades Básicas previstas no Anexo I do RSI (2005), como 
Estado Parte, utilizando os instrumentos de avaliação de capacidades básicas de vigilância e resposta em pontos de entrada (portos e aeroportos) definidos em conjunto pelos países que compõem o bloco.

\section{Referências}

ANVISA. Guia prático para o controle sanitário de viajantes. Brasília: Ministério da Saúde, 2005.

ANVISA. Sagarana: Primeiro ano maio de 2010 a maio de 2011. Brasília: Anvisa, 2011. [online] Disponível na internet na URL: http://portal.anvisa.gov.br/wps/wcm/connect/167d300048173402bbe2bf70623c4ce6/R elatorio Sagarana.pdf?MOD=AJPERES (Acesso em 26.11.2012).

BERLINGUER, Giovanni. Globalização e saúde global. Estudos Avançados, 13(35):21-38, 1999.

BRASIL. Decreto Legislativo $n^{\circ}$ 395, de 9 de julho de 2009. [online] Disponível na internet na

URL: http://www.in.gov.br/imprensa/visualiza/index.jsp?jornal=1\&pagina=11\&data=10/07/20 $\underline{09}$ (Acesso em 12.09.2012).

BRASIL. Lei no 9.782, de 26 de janeiro de 1999. [online] Disponível na internet na URL: http://www.planalto.gov.br/ccivil 03/leis/L9782.htm (Acesso em 22.11.2012).

BRASIL. Lei no 12.663, de 5 de junho de 2012. [online] Disponível na internet na URL: http://www.planalto.gov.br/ccivil 03/ Ato2011-2014/2012/Lei/L12663.htm (Acesso em 12.09.2012).

BRASIL. Ministério da Saúde. Secretaria de Vigilância em Saúde. Centro de informações estratégicas em vigilância em saúde - CIEVS. Brasília: SVS, 2006. [online] Disponível na internet na http://portal.saude.gov.br/portal/arquivos/pdf/apostila cievs bilingue.pdf (Acesso em 10.10.2012).

BRASIL. Nota Técnica nº6/07/DEVEP/SVS/MS. [online] Disponível na internet na URL:

http://portal.anvisa.gov.br/wps/wcm/connect/0608868047458ebf97aed73fbc4c6735/P

AF+Viajantes+Nota+Tecnica.pdf?MOD=AJPERES (Acesso em 28.11.2012).

BRASIL. Portaria $n^{\circ}$ 593, de 25 de agosto de 2000. [online] Disponível na internet na URL: $\quad$ http://www.anvisa.gov.br/institucional/anvisa/regimento.pdf $\quad$ (Acesso em 27.11.2012).

BRASIL. Portaria no 1.865/GM/MS, de 10 de agosto de 2006. [online] Disponível na internet na URL: http://portal.saude.gov.br/portal/arquivos/pdf/portaria1865.pdf (Acesso em 12.09.2012).

BRASIL. Regulamento Sanitário Internacional (2005). Brasília: Anvisa, 2009.

BRASIL. Resolução no 443, de 9 de junho de 2011. [online] Disponível na internet na URL:

http://bvsms.saude.gov.br/bvs/saudelegis/anvisa/2011/res0443 0906 2011.html (Acesso em 30.11.2012). 
BRASIL. RDC $n^{\circ} 2$, de 4 de janeiro de 2013. [online] Disponível na internet na URL: http://www.in.gov.br/visualiza/index.jsp?data=08/01/2013\&jornal=1\&pagina=34\&totalA rquivos $=56$ (Acesso em 09.01.2013).

BUSS, Paulo Marchiori. Globalização, pobreza e saúde. Ciência \& Saúde Coletiva, 12(6):1575-1589, 2007.

CARMO, Eduardo Hage; PENNA, Gerson; OLIVEIRA, Wanderson Kleber. Emergências de saúde pública: conceito, caracterização, preparação e resposta. Estudos Avançados, 22(64):19-32, 2008.

CASTRO, Larissa de Paula Gonzaga. Saúde pública global e o novo Regulamento Sanitário Internacional. Cadernos Iberoamericanos de Direito Sanitário, 1(1):67-78, jan./jun., 2012.

COSTA, Ediná Alves. Vigilância Sanitária e Proteção da Saúde. In: Direito sanitário e saúde pública. v. 1, Brasília: Ministério da Saúde, 2003.

DALLARI, Sueli Gandolfi; VENTURA, Deisy de Freitas Lima. O princípio da precaução: dever do Estado ou protecionismo disfarçado? São Paulo em Perspectiva, 16(2):53-63, 2002.

FERREIRA, Fátima de Paula; CASTRO, Larissa de Paula Gonzaga. O novo Regulamento Sanitário Internacional e o controle da pandemia influenza H1N1 no Brasil. Revista Paradigma, 20(1):205-222, 2011.

FIDLER, David P. Emerging Trends in International Law Concerning Global Infectious Disease Control. Emerging Infectious Diseases, 9(3):285-290, 2003.

GONZALO, Miguel Mínguez. El "nuevo reglamento sanitario internacional" - RSI (2005). Revista Española de Salud Pública, 81(3):239-246, mai./jun. 2007.

MENDOZA, Guillermo J. Avilés. Novo 'Regulamento Sanitário Internacional': Plataforma para governança global da saúde. Ethos Gubernamental, (4):79-99, 2006 $-2007$.

ORGANIZAÇÃO PAN-AMERICANA DE SAÚDE. CSP28/INF/3. 28aㅡ Conferência Sanitária Pan-americana. Washington: OPAS/OMS, 2012.

PERIAGO, Mirta Roses; STEPKE, Fernando Lolas. A Globalização e os dilemas da saúde universal. Ethos Gubernamental, (4):103-110, 2006 - 2007.

PORTAL DA COPA. Câmaras setoriais. (a) Disponível na internet na URL: http://www.copa2014.gov.br/pt-br/sobre-a-copa/camaras-tematicas\#Saúde (Acesso em 24/09/2012).

PORTAL DA COPA. Profissionais de saúde das cidades-sede da Copa do Mundo participam de treinamento em Brasília. (b) Disponível na internet na URL: http://www.copa2014.gov.br/pt-br/noticia/profissionais-de-saude-das-cidades-sede-dacopa-do-mundo-participam-de-treinamento-em (Acesso em 06/12/2012).

TEIXEIRA, Maria Glória [et al]. Vigilância em Saúde: é necessária uma legislação de emergência? Revista de Direito Sanitário, 10(2):126-144, 2009.

VARELLA, Marcelo Dias. Direito Internacional Público. São Paulo: Saraiva, 2010.

VENTURA, Deisy de Freitas Lima. Pandemias e Estado de exceção. In: Anais do VII Congresso Internacional de Direito da USJT. São Paulo : USTJ, 2010. 
Anais dos III Congresso Iberoamericano de Direito Sanitário / II Congresso Brasileiro de Direito Sanitário

WORLD HEALTH ORGANIZATION. Constitution of the World Health Organization. Nova lorque: OMS, 1946. [online] Disponível na internet na URL: http://apps.who.int/gb/bd/PDF/bd47/EN/constitution-en.pdf (Acesso em 12.11.2012).

WORLD HEALTH ORGANIZATION. International Health Regulations (2005). Geneva: Genebra: WHO Press, 2008. 